Retraction

\title{
Retracted: Structural and Electrical Properties of Graphene Oxide-Doped PVA/PVP Blend Nanocomposite Polymer Films
}

\author{
Advances in Materials Science and Engineering \\ Received 18 November 2020; Accepted 18 November 2020; Published 19 January 2021 \\ Copyright (c) 2021 Advances in Materials Science and Engineering. This is an open access article distributed under the Creative \\ Commons Attribution License, which permits unrestricted use, distribution, and reproduction in any medium, provided the \\ original work is properly cited.
}

Advances in Materials Science and Engineering has retracted the article titled "Structural and Electrical Properties of Graphene Oxide-Doped PVA/PVP Blend Nanocomposite Polymer Films" [1] due to figure duplication from the authors' earlier work, which was not cited [2]. The experiments in which these images are said to represent are similar, but not the same: Figure 4(b) in [1], showing scanning electron microscopy of a polymer electrolyte film of PVP/PVA : GO with a ratio of $0.25: 0.2$ is a magnified, high-resolution version of Figure 4(b) in [2] showing a ratio of $0.4: 0.2$.

The authors also reused the images in Figures 4(a) and 4(c) [1] when they attempted to correct another article, which was also retracted due to figure issues [3].

The authors do not agree with the retraction.

\section{References}

[1] S. K. Shahenoor Basha, K. Vijay Kumar, G. Sunita Sundari, and M. C. Rao, "Structural and Electrical Properties of Graphene Oxide-Doped PVA/PVP Blend Nanocomposite Polymer Films," Advances in Materials Science and Engineering, vol. 2018, Article ID 4372365, 11 pages, 2018.

[2] S. K. Shahenoor Basha and M. C. Rao, "Spectroscopic and Discharge Studies on Graphene Oxide Doped PVA/PVP Blend Nanocomposite Polymer Films," Polymer Science, Series A, vol. 60, pp. 359-372, 2018.

[3] International Journal of Polymer Science, "Retracted: "Spectroscopic and Electrochemical Properties of $(1-x)$ [PVA/PVP] : $x\left[\mathrm{MgCl}_{2}\left\{6 \mathrm{H}_{2} \mathrm{O}\right\}\right]$ Blend Polymer Electrolyte Films,"” International Journal of Polymer Science, vol. 2019, Article ID 8095237, 2 pages, 2019. 


\title{
Structural and Electrical Properties of Graphene Oxide-Doped PVA/PVP Blend Nanocomposite Polymer Films
}

\author{
S. K. Shahenoor Basha, ${ }^{1}$ K. Vijay Kumar, ${ }^{2}$ G. Sunita Sundari, ${ }^{1}$ and M. C. Rao $\mathbb{D}^{3}$ \\ ${ }^{1}$ Solid State Ionics Laboratory, Department of Physics, KL University, Guntur 522502, India \\ ${ }^{2}$ Department of Physics, Dayananda Sagar Academy of Technology and Management, Udayapura, Bangalore 560082, India \\ ${ }^{3}$ Department of Physics, Andhra Loyola College, Vijayawada 520008, India
}

Correspondence should be addressed to M. C. Rao; raomc72@gmail.com

Received 10 October 2017; Revised 1 December 2017; Accepted 5 December 2017; Published 6 February 2018

Academic Editor: Peter Majewski

Copyright ( 12018 S. K. Shahenoor Basha et al. This is an open access article distributed under the Creative Commons Attribution License, which permits unrestricted use, distribution, and reproduction in any medium, provided the original work is properly cited.

\begin{abstract}
Graphene oxide $(\mathrm{GO})$ nanoparticles were incorporated in PVA/PVP blend polymers for the preparation of nanocomposite polymer films by the solution cast technique. XRD, FTIR, DSC, SEM, and UV-visible studies were performed on the prepared nanocomposite polymer films. XRD revealed the amorphous nature of the prepared films. Thermal analysis of the nanocomposite polymer films was analyzed by DSC. SEM revealed the morphological features and the degree of roughness of the samples. DC conductivity studies were under taken on the samples, and the conductivity was found to be $6.13 \times 10^{-4} \mathrm{~S} \cdot \mathrm{cm}^{-1}$ for the polymer film prepared at room temperature. A solid-state battery has been fabricated with the chemical composition of $\mathrm{Mg}^{+} /\left(\mathrm{PVA}^{\mathrm{PVP}}\right.$ : $\mathrm{GO}) /\left(\mathrm{I}_{2}+\mathrm{C}+\right.$ electrolyte $)$, and its cell parameters like power density and current density were calculated.
\end{abstract}

\section{Introduction}

Nowadays researchers have aimed at graphene- and graphene oxide- (GO-) based materials due to their excellent potential, thermal, and mechanical properties such as conductive coating, sensors, microwave absorbing, and energy storage devices [1]. After the discovery of graphene and graphene oxide, a focus has been made on the nonvolatile memory devices due to their potential applications [2-4]. Nanocomposite polymer films are prepared by dispersing the nanocomposites in the polymer matrix such as graphite, carbon nanotubes, carbon fiber, nanofillers, and rare earth-doped ions [5]. By doping the nanocomposites in conductive polymers, the enhancement of electrical conductivity is increased at a higher rate [6].

Graphene, a monolayer of hexagonally packed carbon atoms, has revolutionized both the academic and industrial world to greater extent [7]. Such a huge interest may be owned to its novel properties like high modulus and tensile strength, large theoretical specific surface area, almost transparent and excellent conductivity. Out of many possible functionalized forms of graphene and its composites, polymer-based graphene composites are quite promising candidates due to combined improved properties [8]. A flexible supercapacitor is one of the most important energy storage devices which have been extensively explored in these years [9]. Graphene possesses a honeycomb-like structure with $\mathrm{sp}^{2}$-bonded carbon atoms closely packed with oxygen molecules. Graphene has excellent physical and mechanical properties such as high thermal conductivity, tensile strength, high specific surface area, and high mobility of charge carriers [10]. Graphene is also used in many applications such as batteries, solar cells, fuel cells, and supercapacitors [11-13]. Graphene is widely used as nanofiller in polymer composites for several practical applications on large-scale production. The strong interaction formed between the polar molecules of GO is due to the presence of oxygen-containing functional groups to give homogenous dispersion [14]. Graphene-doped polymer nanocomposite films have been studied and reported because of their thermal stability [15], mechanical strength [16], and improved ionic conductivity [17]. 
Magnesium metal has very vast advantages over lithium. It is widely used as anode material in energy storage devices because it is freely available material in the earth crust. When compared to lithium devices, magnesium-based devices have lot of advantages such as low cost, nontoxic, light weight, and higher stability at ambient temperatures. Therefore, magnesium can be replaced with lithium in the fabrication of solid-state batteries [18]. Polyvinyl pyrrolidone (PVP) has chosen because it has excellent characteristics such as optical, mechanical and electrical properties. PVP has ad-chive nature. Thus, it may be used in electronic circuit boards and display device applications. PVP has good compatibility and can easily form films with large internal area [19]. PVP is easily soluble in distilled water and in organic solvents. It has amorphous nature. Because of its low scattering loss, it can be more useful for optical applications, resulting in the good dispersion and surface formation [20].

In recent years, polymers such as polyvinyl alcohol (PVA), polyvinylidene fluoride (PVdF), polyethylene glycol (PEG), polyvinyl chloride (PVC), polyacrylonitrile (PAN), polyvinyl pyrrolidone (PVP), and polyvinyl sulfone (PVS) have been prominently used in the development of solid polymer electrolytes (SPEs). In general, SPEs possess ionic conductivity, electrochemical stability, and transport properties similar to their liquid counter parts along with better dynamical properties suitable for electrochemical applications. Among the listed polymeric hosts, polyvinyl alcohol has been intensely investigated. Polyvinyl alcohol (PVA) appears to be very attractive material for preparing proton-conducting polymer electrolyte because this polymer can function as an excellent methanol barrier. Polyvinyl alcohol (PVA) is used in the preparation of nanocomposite polymer films due to its excellent film formation and high mechanical strength. Due to its polymeric behavior, it can be widely used in energy storage devices [21].

In the present investigation, nanocomposite polymer films were prepared by dispersing GO nanoparticles with PVA/PVP blend polymers to improve the ionic conductivity which is suitable for battery application. The nanocomposite polymer films have better electrochemical stability towards a metal anode and an enhanced cation transport number $[22,23]$. On the other hand, in terms of electrical conductivity, graphene oxide is often described as an electrical insulator due to the disruption of its $\mathrm{sp}^{2}$ bonding networks [24]. The novelty of this present work is to prepare and characterize the graphene-based nanocomposite polymer electrolytes, which can be used for energy storage devices with improved physical, electrical, and mechanical properties. Polymer-based solid-state batteries have been widely studied and investigated. However, the ionic conductivity of inorganic salt-doped polymer electrolytes is relatively low, that is, $10^{-5} \mathrm{~S} / \mathrm{cm}$. These low conductive polymer electrolytes are not used in any electrochemical devices. To overcome these problems, graphene-based nanocomposite films were prepared by cost-effective solution cast technique in order to improve their physical and electrochemical properties. The main objective of the present study is to prepare blend polymer electrolyte of PVA/PVP with different weight percent (wt.\%) ratios of GO. The prepared samples were subsequently characterized by XRD, SEM, FTIR, DSC, and $\mathrm{UV}$-visible studies. Electrical measurements were also carried out on the films for solid-state battery application.

\section{Experiment}

2.1. Chemicals Required. The materials used in the present investigations and their specifications were graphene: formula weight: 4,239.48 g/mol, carbon (anhydrous) $>50.0 \%$, bulk density: $\sim 1.8 \mathrm{~g} / \mathrm{cm}^{3}$, oxidation: $4-10 \%$; polyvinyl alcohol (PVA): average molecular weight: 89,000-98,000, molecular weight of repeat unit: $44.00 \mathrm{~g} / \mathrm{mol}$; and polyvinyl pyrrolidone (PVP): average molecular weight $=36,000-40,000$, molar mass of PVP $112.88902 \pm 0.00010 \mathrm{~g} / \mathrm{mol}$. All chemicals used in the present investigation were purchased by ourself from Sigma Aldrich chemicals Ltd., India.

2.2. Preparation of Nanocomposite Polymer Films. Nanocomposite polymer films were prepared with the combination of GO, PVA, and PVP. Take $200 \mathrm{ml}$ round-bottomed flask and add $30 \mathrm{ml}$ of distilled water with blend polymers PVA/PVP: wt.\% $(0.20 / 0.20,0.25 / 0.25$, and $0.30 / 0.30)$ (equal wt.\% ratios of PVA/PVP). Stir all the mixtures till the polymers get dissolved in water. Later, reduced nanoparticles of GO: $\mathrm{x} \%(0.1$, 0.2 , and $0.3 \mathrm{~g}$ ) were added to the homogenous mixture to sonicate the solution. The obtained homogenous solution was sonicated with the frequency of $20 \mathrm{kHz}$ (Sonic and Material Vibra cell VC600; Sonic and Material Inc.), $I=0.012 \mathrm{~W} \cdot \mathrm{cm}^{-2}$ for $20 \mathrm{~min}$ at room temperature, to get fine dispersion, which was poured in polypropylene dishes and placed in hot air oven at $70^{\circ} \mathrm{C}$. A fine nanocomposite polymer thin film was obtained. The prepared film was kept in a desiccator until further test.

2.3. Characterization. X-ray diffraction (XRD) studies were performed by using a Philips analytical X'pert diffractometer in the diffraction " $2 \theta$ " angular range $10-70^{\circ}$ with nickelfiltered CuKa radiation $(\lambda=1.5403 \AA$ ). Fourier Transform Infrared (FTIR) spectra were recorded with the help of a Perkin Elmer Alpha-E spectrophotometer and heater coil of the furnace recorded in the wave number range $450-4000 \mathrm{~cm}^{-1}$. The thermal analysis and heat flow in a sample were measured by the differential scanning calorimeter (DSC), Q-2920, TA, and which gives the information about the quantitative and qualitative analysis. Morphological studies were carried out on the prepared samples with different resolutions by using FE-SEM, Carl Zeiss, Ultra 55 model. Optical absorption studies were performed at room temperature using JASCO V-670 Spectrophotometer for the prepared samples in the wavelength range $200-800 \mathrm{~nm}$. The DC conductivity was measured by screening the current with the help of a Keithley electrometer (Model 6514). Discharge characteristics were studied by fabricating a solidstate battery with the configuration of $\mathrm{Mg}^{+}$(anode)/polymer electrolyte/(I + C + electrolyte)/(cathode) for different wt.\% ratios of the prepared samples at room temperature for a constant load of $100 \mathrm{k} \Omega$. 


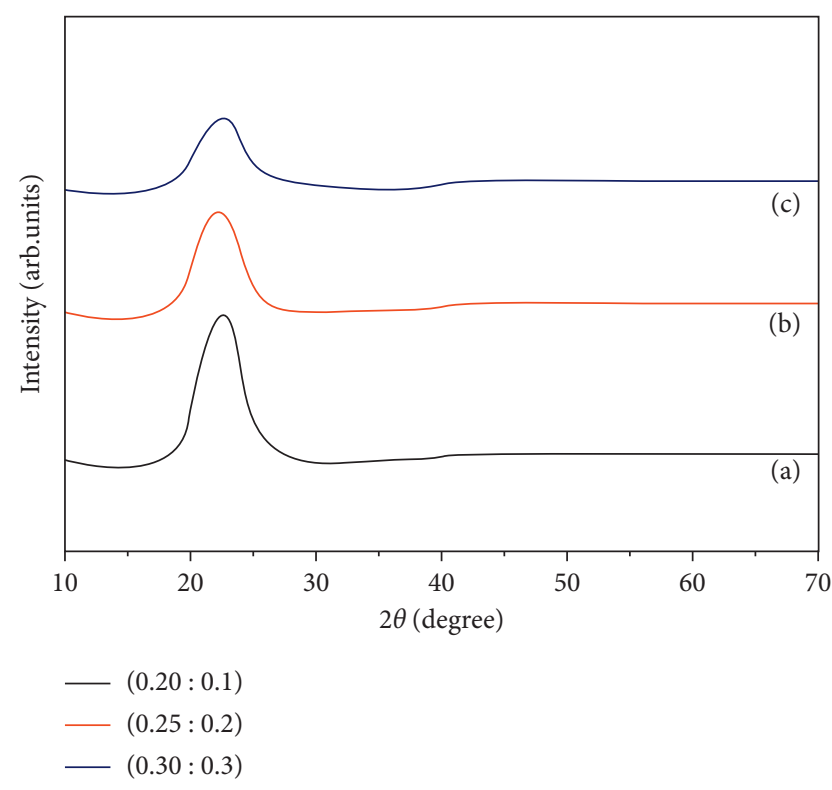

FIGURE 1: XRD analysis of polymer electrolyte films for different PVP/PVA : GO wt.\% ratios of $(0.20: 0.1),(0.25: 0.2)$, and $(0.30: 0.3)$.

\section{Results and Discussion}

3.1. XRD Analysis. An X-ray diffraction pattern is essential to obtain the detailed structure and knowledge on the given material. The X-ray diffraction pattern of PVA/PVP : GO is shown in Figure 1. The parallel beam XRD technique with polycapillary collimating optics can be used to enhance powder XRD experiments. In most reflection arrangements, the sample is typically a flat plate, whereas in transmission arrangement the specimen is traditionally placed in a glass capillary or in the form of a thin foil. The most common reflection arrangement is the parafocusing Bragg-Brentano $\theta: 2 \theta$ geometry with a fixed line source and an angular motion of the specimen $(\theta)$ and receiving slit $(2 \theta)$. The divergence of the line source on the sample is set by aligning the tube at a takeoff angle $\left(\sim 6^{\circ}\right)$ and controlled by a divergence slit between the sample and X-ray tube. The radial distance between the X-ray source and the specimen is fixed equal to the radial distance between the specimen and the receiving slit. The diffraction peak showed at $2 \theta=20.2^{\circ}$ corresponds to the hexagonal lattice of (002) plane, indicating intercalated $\mathrm{H}_{2} \mathrm{O}$ functionalities in the graphenebased nanocomposite polymer films [25]. Broadening of the peak was attributed to reduction in the crystalline nature of PVA/PVP (semicrystalline) due to cross-linking formation with GO. When GO is dispersed in the polymer matrix, the nanofiller particles get randomly and uniformly distributed in the entire volume of the polymer blend. When the concentration of the filler incorporated in the electrolyte is low, these filler grains are well dispersed from each other. These facilities the amorphous phase in the polymer matrix, by perturbing polymer chain packing and reducing crystalline nature in the polymer. The amorphous phase improves the free volume of the matrix, which makes the polymer chain more flexible and dynamic resulting in the enhancement of ionic conductivity. The addition of GO reduced the crystalline nature of the PVA/PVP membrane and shifted the peak to lower value. The intensity of the peak is slightly changed by doping with the wt.\% of GO to the polymer.

It is clear from Figure 1 that the sharp peak is decreased due to the semicrystalline nature of the nanocomposite polymer films by doping GO with $0.1,0.2$, and 0.3 wt. $\%$ ratios. No sharp peak was observed for $0.3 \mathrm{wt} . \%$ ratio due to the complete dispersion of GO in the polymer which in turn the semicrystalline to amorphous phase. Thus, the nanocomposite polymer films are more flexible and result in an increase in segmental motion, which enhances the ionic conductivity of the film doped with $0.3 \mathrm{wt} . \%$ ratio of GO [26]. It is also observed from Table 1 that the full width half maxima (FWHM) decreases with the increase of the wt.\% ratio of GO. From the XRD spectra, it is also observed that the crystalline peak of pure PVA/PVP gradually decreases with the increase of GO concentration. The decrement in the crystalline nature can be attributed to the increment of GO wt.\%; as a result, intermolecular interaction takes place between PVA/PVP chains and GO, thereby resulting in increase of the amorphous nature of the films. As the GO wt.\% ratio increases in the blend polymer, the intensity of the peak seems to be decreased. This change in the intensity of the peak is due to dispersion of GO in the blend polymer composites, which enhances the high ionic conduction in polymer chains, and also the full width half maxima (FWHM) changes as the wt.\% ratio of GO changes.

3.2. FTIR Studies. FTIR is a versatile instrument to identify the chemical complex nature among the polymer matrix and encapsulation of different elements in functional groups [27]. FTIR spectra of PVA/PVP : GO are shown in Figure 2. When the two polymers are mixed, the interaction between PVA/PVP is expected through interchain hydrogen bonding between the hydroxyl group of PVA and carbonyl group of $\mathrm{PVP}$, which arises due to the presence of $\mathrm{OH}$ group and the hydrogen bond formation. In order for a vibrational mode in a sample to be "IR active," it must be associated with changes in the dipole moment. A molecule can vibrate in many ways, and each way is called a vibrational mode. For molecules with $\mathrm{N}$ number of atoms, linear molecules have $3 \mathrm{~N}-5$ degrees of vibrational modes, whereas nonlinear molecules have $3 N-6$ degrees of vibrational modes (also called vibrational degrees of freedom).

The bands in the wave number range $2900-3600 \mathrm{~cm}^{-1}$ correspond to the outer phase vibration oscillation of the hydroxyl group $(\mathrm{O}=\mathrm{H})$, which are completely mixed with the polymer further. The band positions observed at 698, 1201,1302 , and $1748 \mathrm{~cm}^{-1}$ were corresponding to $\mathrm{C}-\mathrm{O}$ bending, $\mathrm{C}-\mathrm{O}$ stretching of hydroxyl group, and $\mathrm{C}=\mathrm{O}$ stretching vibrations of carboxyl group, respectively [28]. With the increase in the wt.\% ratio, the stretching and bending intensity of the peaks slightly shifts to 727,1220 , and $1691 \mathrm{~cm}^{-1}$. The symmetric and asymmetric stretching modes of ether groups were observed at 2897 and $3210 \mathrm{~cm}^{-1}$ and the 
TABLE 1: FWHM values of PVP/PVA : GO nanocomposite polymer films.

\begin{tabular}{lc}
\hline Nanocomposite polymer films & FWHM values \\
\hline PVP/PVA : GO $(0.20: 0.1)$ & 7.10233 \\
PVP/PVA : GO $(0.25: 0.2)$ & 9.24033 \\
PVP/PVA : GO $(0.30: 0.3)$ & 13.89486 \\
\hline
\end{tabular}

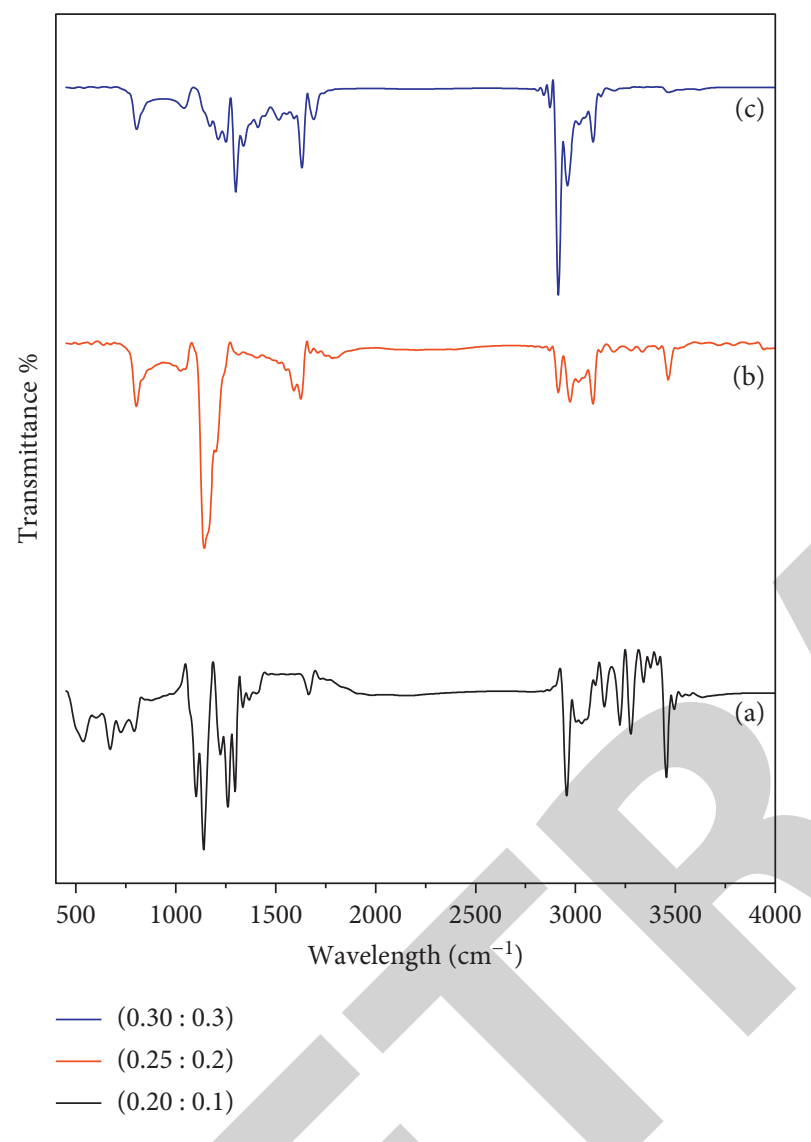

FIGURE 2: FTIR spectra of polymer electrolyte films for different PVP/PVA : GO wt.\% ratios of $(0.20: 0.1),(0.25: 0.2)$, and $(0.30: 0.3)$.

band at $3395 \mathrm{~cm}^{-1}$ corresponds to the $\mathrm{O}-\mathrm{H}$ stretching vibration of GO, respectively. FTIR spectra revealed the vibrational oscillation of the hydroxyl group of GO and blend polymers. By increasing the wt.\% ratio of GO, the intensities of the peaks have been decreased and broadened. This concludes the increase in the interlayer distance between the polymer chains. As a result, GO can easily penetrate into the hydroxyl group of PVA and carbonyl group of PVP.

3.3. DSC Analysis. Differential scanning calorimetry is an effective tool for analyzing the thermal analysis of the materials such as glass transition temperature $\left(T_{\mathrm{g}}\right)$ and melting temperature $\left(T_{\mathrm{m}}\right)$ in the polymer electrolytes. The mass employed in this analysis is usually around $3-8 \mathrm{mg}$. But it is independent of the transition exhibited by the sample. When a dynamic underlying heating rate is chosen, there are two main types of experiments available: modulated heat-

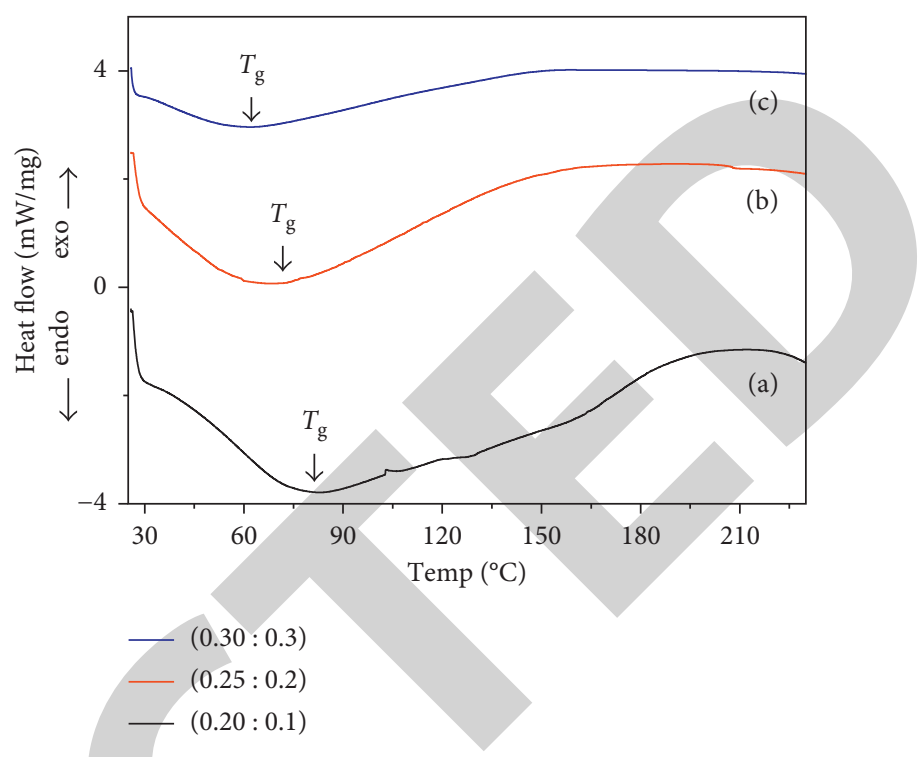

FIGURE 3: DSC spectra of polymer electrolyte films for different PVP/PVA : GO wt.\% ratios of $(0.20: 0.1),(0.25: 0.2)$, and $(0.30: 0.3)$.

cool or modulated heat-only and the temperature profiles. If the period and heating rate were 60 seconds and $2^{\circ} \mathrm{C} / \mathrm{min}$, respectively, the maximum heat amplitude would be only $\pm 0.318^{\circ} \mathrm{C}$. Amplitudes less than this value will still provide heat-only conditions, but amplitude greater than this value will represent a modulated heat-cool condition. If a value for a heating rate of $2.5^{\circ} \mathrm{C} / \mathrm{min}$ is required, adding the values for $2.0^{\circ} \mathrm{C} / \mathrm{min}$ and $0.5^{\circ} \mathrm{C} / \mathrm{min}$ will provide the required value. The amplitudes are minimum for the heating rate of $0^{\circ} \mathrm{C} / \mathrm{min}$.

The DSC spectra of PVA/PVP : GO polymer films are shown in Figure 3. An endothermic peak of nanocomposite polymer films indicates the glass transition temperature [29]. This concludes that GO is dispersed in the PVA/PVP matrix. The nanofiller particles get randomly, uniformly distributed in the entire volume of the polymer blend and also observed that the glass transition temperature is found to be $85^{\circ} \mathrm{C}$. This results in the amorphous nature of the films. On increasing the wt.\% ratio, the melting temperature is decreased and found to be 60 and $55^{\circ} \mathrm{C}$. The decrease in $T_{\mathrm{g}}$ helps to soften the polymer backbone where the pinholes are formed in the polymer chains, thereby increasing in the movement of ions freely through the material. Figure 3 depicts the existence of dominant endothermic peaks in the temperature ranging from 60 to $95^{\circ} \mathrm{C}$, which corresponds to the semicrystalline phase formation in the polymeric films. The polymer electrolyte of PVA/PVP : GO $(0.30: 0.3)$ exhibits the lower $T_{\mathrm{g}}$ value $\left(55^{\circ} \mathrm{C}\right)$ indicating more amorphous nature and more flexibility compared with the other polymer electrolytes. This inference was confirmed by XRD analysis. Due to lubricating effect of the polymer chains, the decrease in $T_{\mathrm{g}}$ takes place at lower value. Usually, the amorphous nature of the polymer and its flexibility depend on the glass transition temperature. From the figure, it is clearly observed that as increasing the wt.\% ratio of GO concentration to the blend polymer, the glass transition temperature is decreased predominantly. 


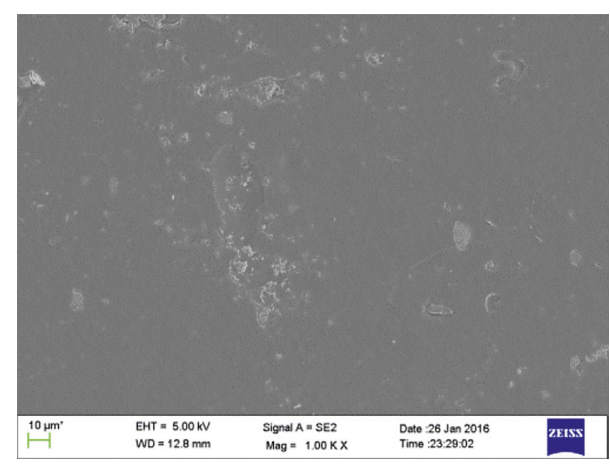

(a)

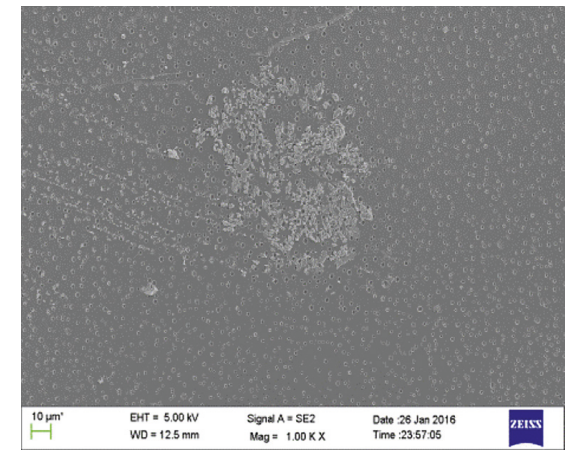

(b)

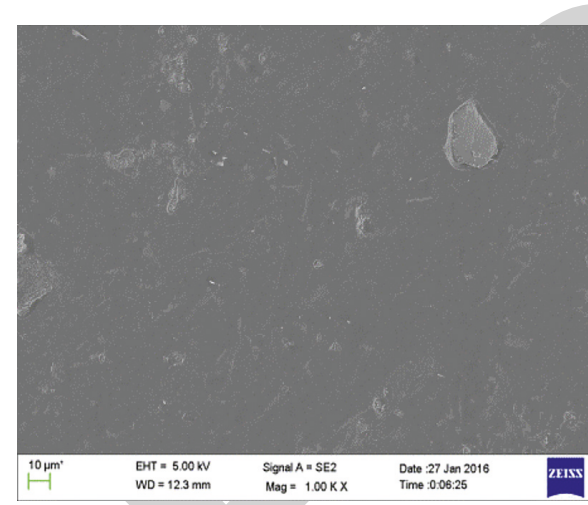

(c)

FIGURE 4: SEM images of polymer electrolyte films for different PVP/PVA : GO wt.\% ratios of (a) $(0.20: 0.1)$, (b) $(0.25: 0.2)$, and (c) $(0.30: 0.3)$.

This clearly denotes the increment in the amorphous phase of the film. This amorphous phase makes the electrolyte more flexible, resulting in an increase in segmental motion of the polymer which favors high ionic conduction [30].

3.4. SEM Analysis. Scanning electron microscope is a very important instrument to analyze and examine the microstructure and morphological surface of the sample. SEM micrographs of the surface and cross section of PVA/PVP : GO blend polymer films are shown in Figures $4(\mathrm{a})-4(\mathrm{c})$. The images revealed the morphological phase of

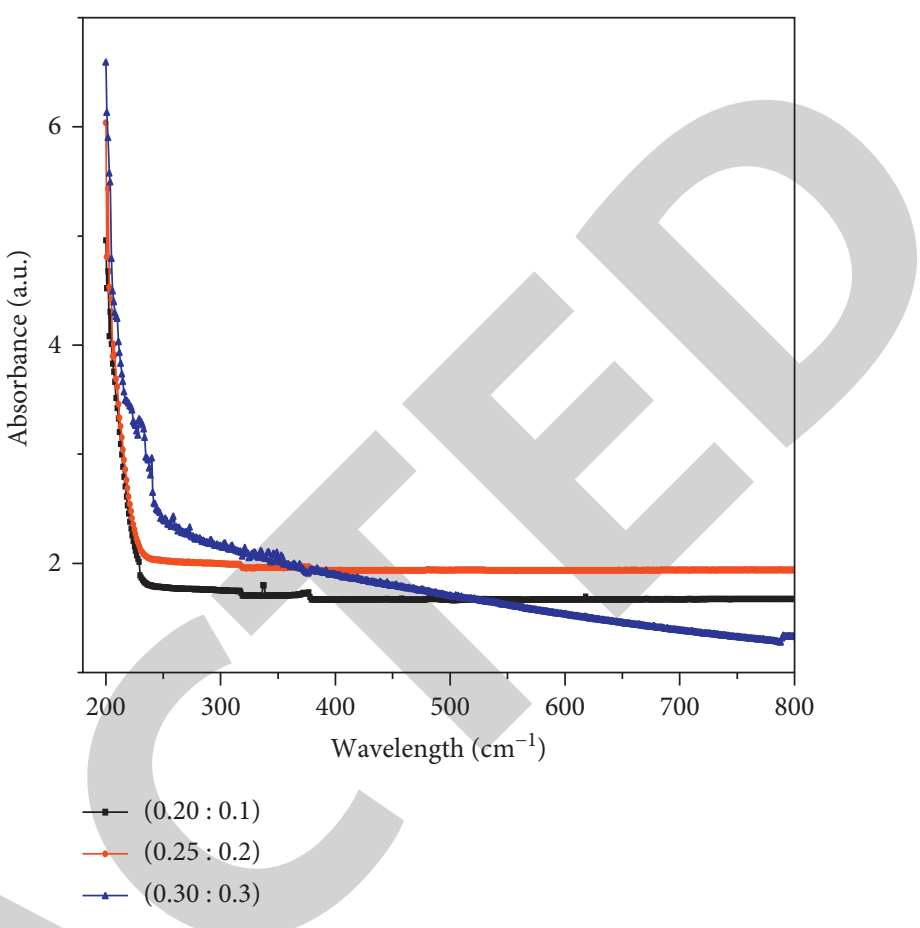

FIGURE 5: UV-visible spectra of polymer electrolyte films for different PVP/PVA : GO wt.\% ratios of $(0.20: 0.1),(0.25: 0.2)$, and $(0.30: 0.3)$.

the nanocomposite polymer electrolyte system. It was also observed that small chunks were formed due to the dispersion of GO in the polymer matrix. As mentioned in Introduction, pure graphene is hydrophobic and has no appreciable solubility in most of the solvents. When the GO is dispersed in the polymer matrix, the filler particles get randomly and uniformly distributed in the entire volume of the polymer blend. When the concentration of the filler incorporated in the electrolyte is low, these filler grains are well dispersed from each other. In the SEM analysis, the phases are observed due to the uneven distribution of GO in the PVA/PVP polymer matrix with different wt.\% ratios (0.1, 0.2 , and 0.3 ), which is clearly observed in Figures 4(a) and 4(b). But in Figure 4(c) for 0.3 wt.\% ratio, dispersion takes place and no phase separation has been observed in the host polymer which enhances the ionic conductivity. As the wt.\% of GO increases, the degree of roughness of the films decreases. This shows the amorphous nature of the film. The higher level of GO in PVP/PVA will result in better dispersion of $\mathrm{GO}$, which is confirmed from the SEM images. This agrees to the XRD analysis. The compatibility of the blend PVA/PVP matrix with GO is uniform and homogenous when the GO content is about 0.3 wt. $\%$ ratio. Thus, it confirms that GO was exfoliated within the PVA/PVP matrix and also revealed the heterogeneous phase of nanocomposite polymer electrolyte systems.

3.5. Optical Absorption Studies. UV-visible spectroscopy is a very important tool used to identify the temperaturedependent vibrational bonds in the UV region, and the 
TABLE 2: Optical bandgap values of PVP/PVA : GO nanocomposite polymer films.

\begin{tabular}{|c|c|c|c|}
\hline \multirow{2}{*}{ Nanocomposite polymer films } & \multicolumn{2}{|c|}{ Optical bandgap } & \multirow{2}{*}{ Absorption edge } \\
\hline & Direct $(\mathrm{eV})$ & Indirect $(\mathrm{eV})$ & \\
\hline PVP/PVA : GO (0.20: 0.1$)$ & 5.42 & 4.63 & 5.10 \\
\hline PVP/PVA : GO (0.25: 0.2) & 5.10 & 4.49 & 4.95 \\
\hline PVP/PVA : GO (0.30: 0.3$)$ & 4.96 & 4.28 & 4.45 \\
\hline
\end{tabular}

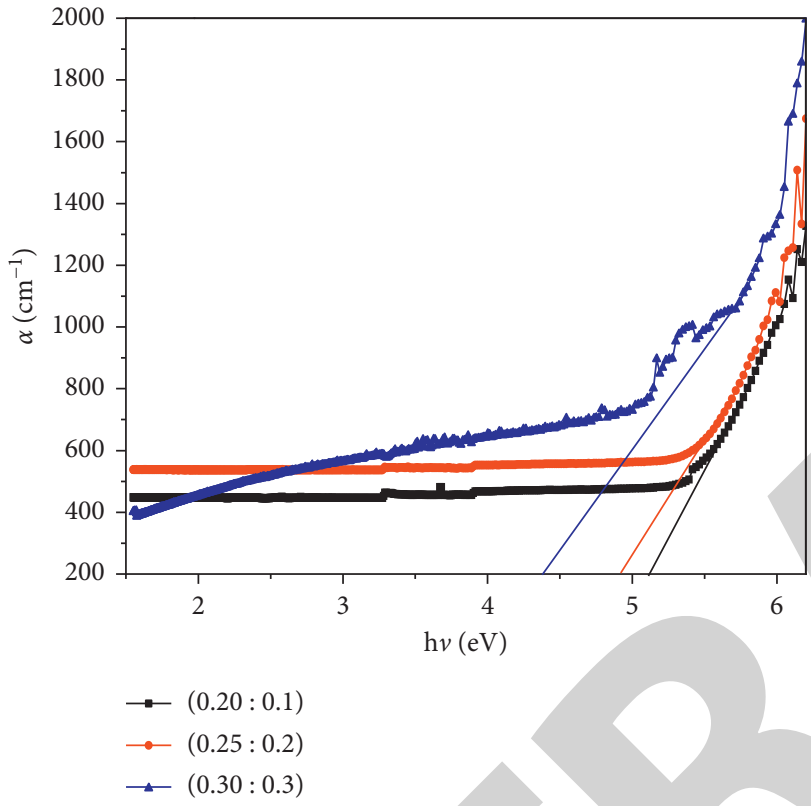

FIGURE 6: $\alpha$ versus h $v$ plots of polymer electrolyte films for different PVP/PVA : GO wt.\% ratios of $(0.20: 0.1),(0.25: 0.2)$, and $(0.30$ : $0.3)$.

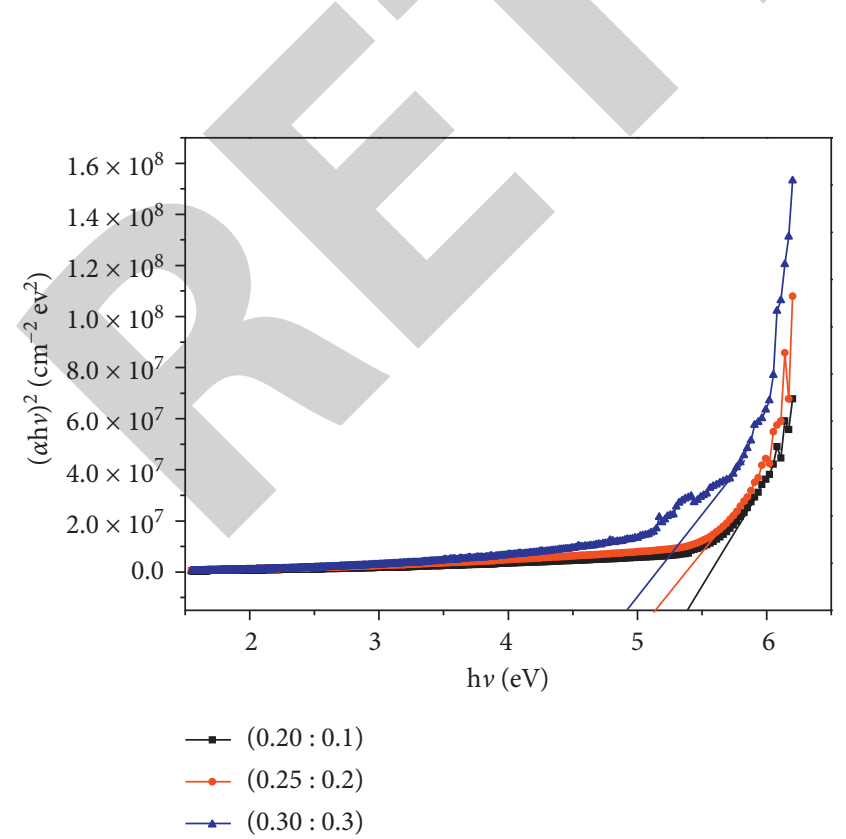

Figure 7: $\alpha$ versus $(\alpha \mathrm{h} v)^{2}$ plots of polymer electrolyte films for different PVP/PVA : GO wt.\% ratios of $(0.20: 0.1),(0.25: 0.2)$, and $(0.30: 0.3)$.

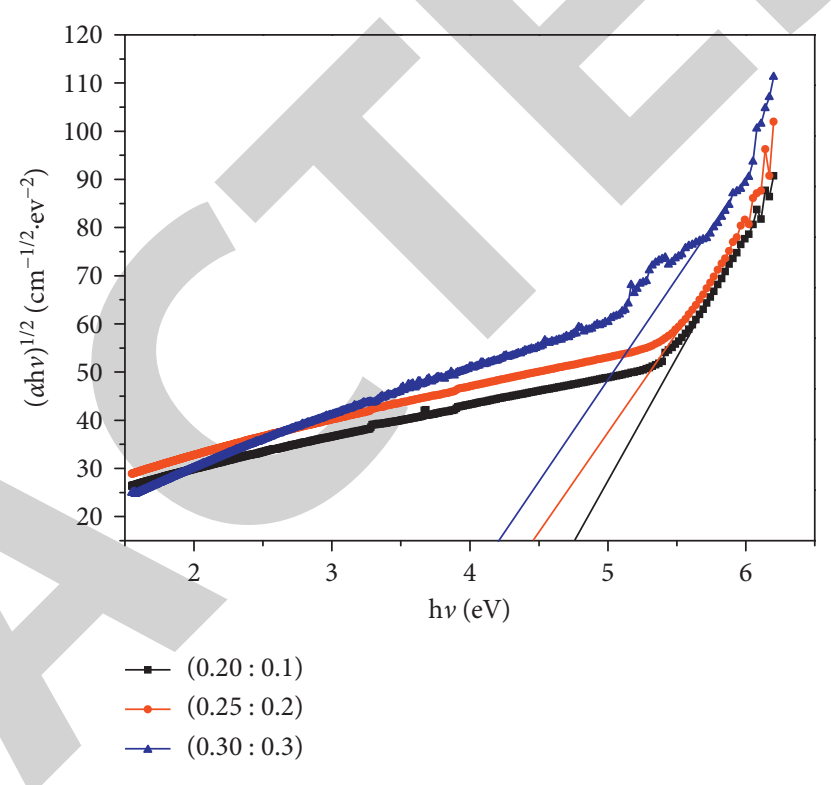

Figure 8: $\alpha$ versus $(\alpha \mathrm{h} v)^{1 / 2}$ plots of polymer electrolyte films for different PVP/PVA : GO wt.\% ratios of $(0.20: 0.1),(0.25: 0.2)$, and $(0.30: 0.3)$

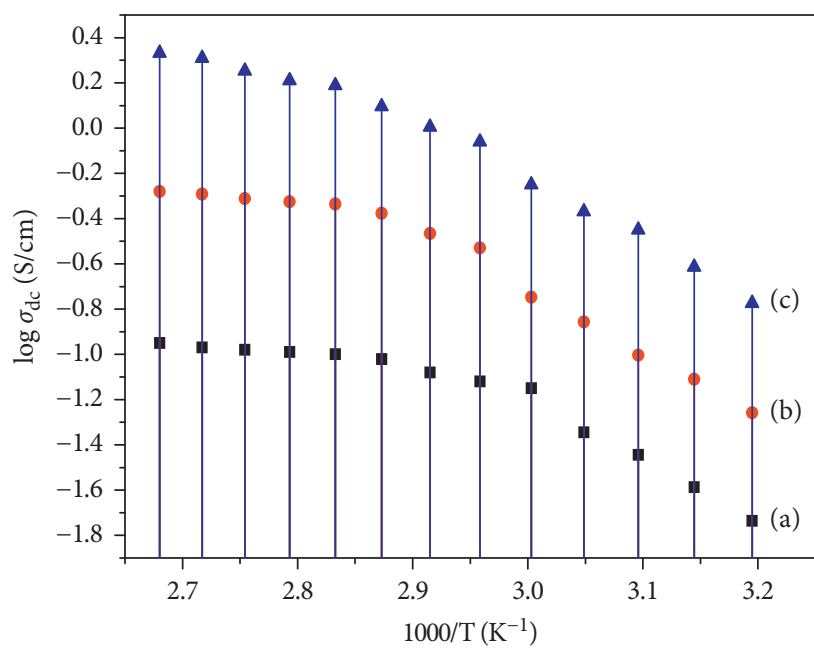

- $(0.20: 0.1)$

- $(0.25: 0.2)$

$\Delta(0.30: 0.3)$

FIGURE 9: DC-conductivity plots of polymer electrolyte films for different PVP/PVA : GO wt.\% ratios of $(0.20: 0.1),(0.25: 0.2)$, and $(0.30: 0.3)$. 
TABLE 3: DC conductivity values of PVP/PVA : GO nanocomposite polymer films.

\begin{tabular}{lcc}
\hline Nanocomposite polymer films & Conductivity values at $300 \mathrm{~K}\left(\mathrm{~S} \cdot \mathrm{cm}^{-1}\right)$ & ${\text { Conductivity values at } 373 \mathrm{~K}\left(\mathrm{~S} \cdot \mathrm{cm}^{-1}\right)}^{-1}$ \\
\hline PVP/PVA : GO $(0.20: 0.1)$ & $3.02 \times 10^{-6}$ & $2.26 \times 10^{-5}$ \\
PVP/PVA : GO $(0.25: 0.2)$ & $1.19 \times 10^{-6}$ & $1.82 \times 10^{-5}$ \\
PVP/PVA : GO $(0.30: 0.3)$ & $5.23 \times 10^{-5}$ & $6.13 \times 10^{-4}$ \\
\hline
\end{tabular}

clusters exhibit the characteristic vibrational modes in energy level. Figure 5 shows the absorbance spectra of PVA/PVP : GO with different wt.\% ratios in the wavelength range $200-800 \mathrm{~nm}$. The absorption peak which is observed in the wavelength region $360-380 \mathrm{~nm}$ corresponds to $\pi-\pi^{*}$ transition of the $\mathrm{C}=\mathrm{C}$ bond of GO. This is attributed to the surface plasmon bond where the electrons are exited from energy level [31]. The optical bandgap values have been determined by extrapolating the steep portion of the absorption curve to intercept the photon energy axis at a certain point. For different wt.\% compositions, the absorption edge has been determined and revealed that the shift in the absorption edge was decreased arbitrarily.

Optical analysis is used to identify the optical bandgap of the materials in the transmitting radiation. The absorption coefficient $(\alpha)$ was calculated from the absorbance $(\mathrm{A})$ value by using the following equitation:

$$
I=I_{0} \exp (-\alpha x) .
$$

Hence,

$$
\ln \left(\frac{I_{0}}{I}\right)=\alpha x, \quad \alpha=2.303\left(\frac{A}{x}\right) .
$$

In general, semiconductors and insulators are divided into two types: (i) direct bandgap and (ii) indirect bandgap. If the top of the valence band and bottom of the conduction band are the same, then the direct bandgap exists; if it is not the same, then the indirect bandgap transitions are obtained [32]. The direct, indirect bandgaps, and absorption edge values are shown in Table 2. To calculate bandgap energy values, graphs were plotted between $\alpha,(\alpha \mathrm{h} v)^{2}$, and $(\alpha \mathrm{h} v)^{1 / 2}$ as a function of hv. Figure 6 shows that the optical absorption spectra of $\alpha$ versus h $v$ for $0.1,0.2$, and $0.3 \mathrm{wt} . \%$ of PVA/PVP : GO films lie at 5.10, 4.95, and $4.45 \mathrm{eV}$.

The direct bandgap transitions can be determined by the following equitation [33]:

$$
\alpha \mathrm{h} v=\mathrm{C}\left(\mathrm{h} v-E_{g}\right)^{1 / 2}
$$

where $E_{g}$ is the bandgap, $C$ is a constant dependent on the specimen structure, $\alpha$ is the absorption coefficient, $v$ is the frequency of incident light, and $\mathrm{h}$ is the Planck constant. Figure 7 shows the direct bandgap of $(\alpha \mathrm{h} v)^{2}$ versus $\mathrm{h} v$ curves, which indicate that the values lie at 5.42, 5.10, and $4.96 \mathrm{eV}$. However, indirect transitions can be determined by the following equitation:

$$
\alpha \mathrm{h} v=\mathrm{A}\left(\mathrm{h} v-E_{g}-E_{p}\right)^{2}+\mathrm{B}\left(\mathrm{h} v-E_{g}-E_{p}\right)^{2},
$$

where $E_{p}$ is the energy of the photon associated with the transition and $\mathrm{A}$ and $\mathrm{B}$ are the constants depending on the
TABLE 4: Transference number of PVP/PVA : GO nanocomposite polymer films.

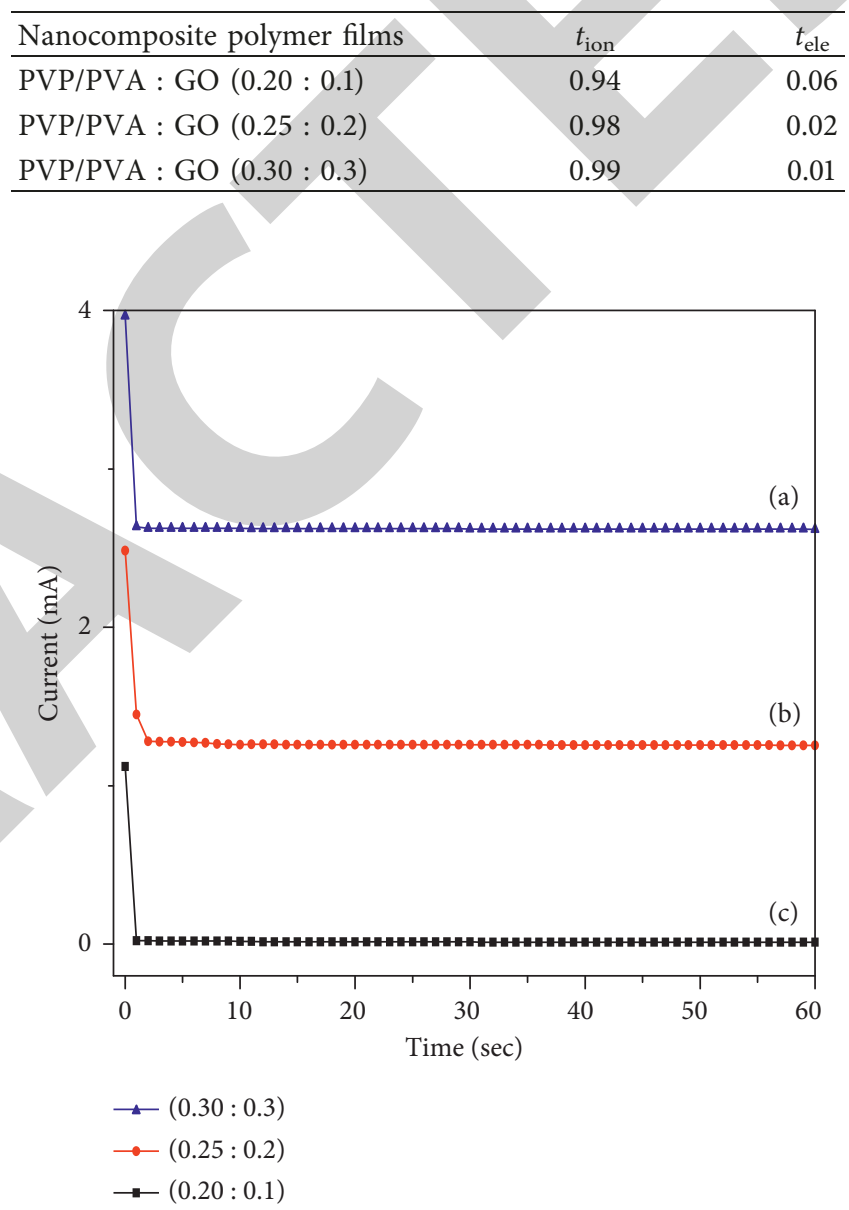

FIGURE 10: Transference number of polymer electrolyte films for different PVP/PVA : GO wt.\% ratios of $(0.20: 0.1),(0.25: 0.2)$, and $(0.30: 0.3)$.

band structure. Figure 8 represents the indirect bandgap values of $(\alpha \mathrm{h} v)^{1 / 2}$ versus $\mathrm{h} v$ curves, which indicates the values lie at 4.63, 4.49, and 4.28, respectively. From the obtained values, it is clear that incorporation of small amount of GO dopant in a host lattice results in the decrease of activation energy in polymer chain such that the ionic conductivity is increased. The optical properties revealed that for the composition of $0.3 \mathrm{wt} . \%$, the bandgap energy is the lowest among all ratios. As a result, the band edge, direct bandgap, and indirect bandgap values showed a decrease with the increase of wt.\% of GO, which is responsible for the defects in the polymer films. These defects produce the localized states in the optical bandgap [34-36]. 


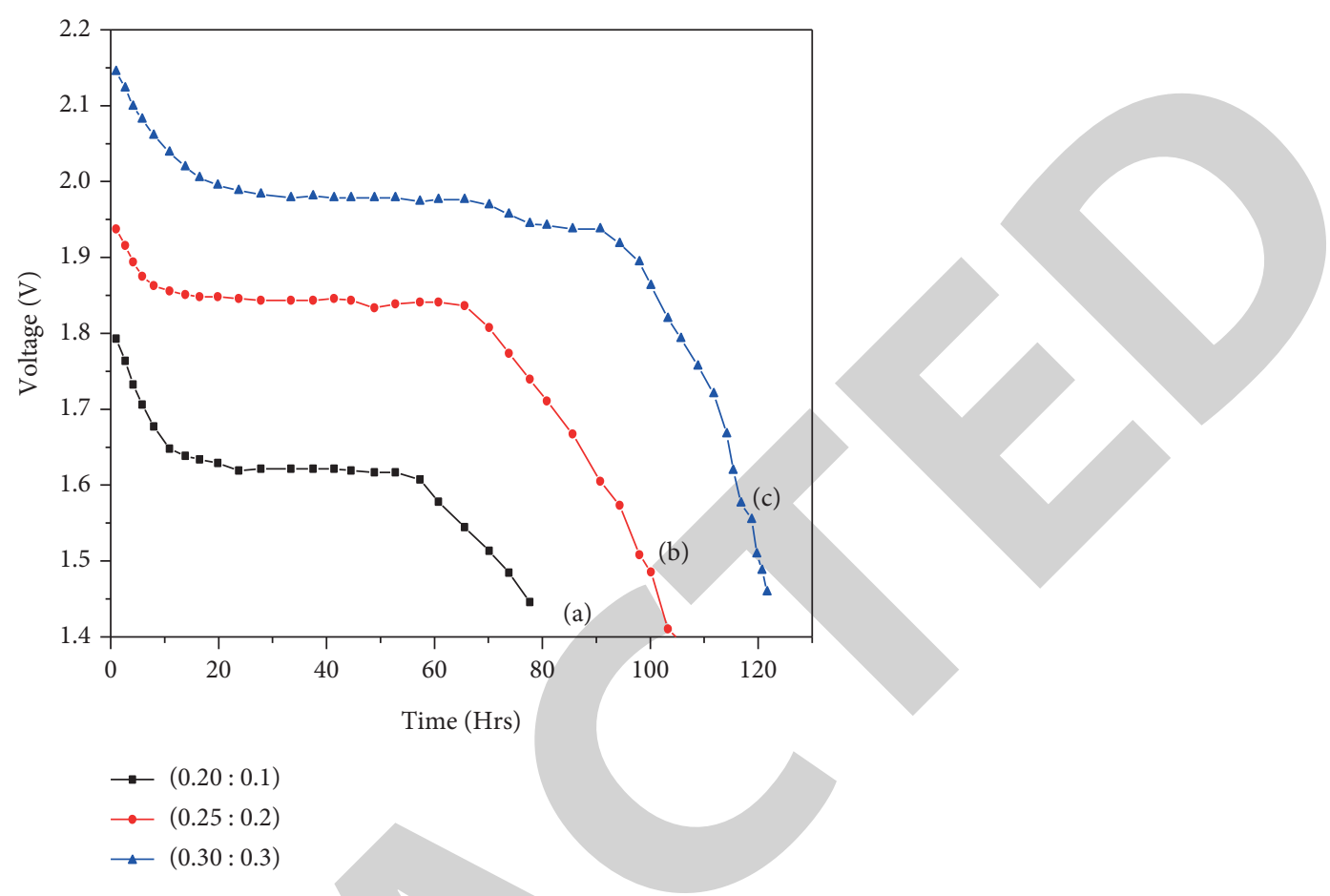

Figure 11: Discharge characteristics of polymer electrolyte films for different PVP/PVA : GO wt.\% ratios of $(0.20: 0.1)$, (0.25: 0.2$)$, and $(0.30: 0.3)$.

3.6. DC Conductivity Studies. The variation of temperature with conductivity of nanocomposite polymer films was studied in the temperature range $303-373 \mathrm{~K}$. The conductivity of blend polymers PVA/PVP was found to be increasing with respect to temperature by adding the GO nanoparticles, which is shown in Figure 9. The data revealed that the conductivity of PVA/PVP : GO is $3.02 \times 10^{-6} \mathrm{~S} \cdot \mathrm{cm}^{-1}$ at room temperature and its value increases sharply to $2.26 \times 10^{-5} \mathrm{~S} \cdot \mathrm{cm}^{-1}$ at $373 \mathrm{~K}$ and for other wt. $\%$ ratios the values are found to be increasing from $1.19 \times 10^{-6}$ to $1.82 \times 10^{-5}$ and $5.23 \times 10^{-5}$ to $6.13 \times 10^{-4} \mathrm{~S} \cdot \mathrm{cm}^{-1}$ with $0.1,0.2$, and $0.3 \mathrm{wt} . \%$ ratios, respectively. From these values, it is observed that the conductivity increases by 2 orders with increasing wt.\% ratio of PVA/PVP : GO (0.1, 0.2, and 0.3). From the figure, it is clear that as the temperature increases, the conductivity increases predominantly [37]. The ionic conductivity of the blend polymer nanocomposite films is increased with the addition of GO wt.\% concentration. But, further addition of GO may decrease the conductivity at a higher concentration because of segregations of ions, which decreases overall mobility. Thus, the conductivity reduces [38]. The increase in conductivity with temperature was explained by the Arrhenius plots; as the temperature increased, the conductivity of the electrolyte films also increased. This favors hopping mechanism between the coordinating sides, local structure relaxation, and segmental motion of the polymer. This enhances the segmental motion of the ions in the polymer matrix. The DC conductivity is calculated by the Arrhenius relation,

$$
\sigma_{\mathrm{dc}}=\frac{i \times t}{V \times A}
$$

where $i$ is the current, $t$ is the thickness of the film, $V$ is the applied voltage, and $A$ is the area of the cross section of the film. The obtained DC conductivity values are mentioned in Table 3.

3.7. Transference Number. The transport (transference) number $(t)$ of the samples indicates the sum of current carried by anions, cations, or electrons in terms of the total conductivity $(\sigma)$. The ionic transference number is defined as the ratio of transference number of any particle/ion to total conductivity $\left(\sigma_{T}\right)[39,40]$. The electronic transference number is defined as the ratio of the transference number of electron/hole conductivity to the total conductivity $\left(\sigma_{T}\right)$. The transport properties have been calculated by the following equation using Wagner's polarizing technique (Table 4):

$$
\begin{aligned}
& t_{\text {ion }}=i_{t}-\frac{i_{\text {ele }}}{i_{t}}, \\
& t_{\text {ele }}=\frac{i_{\text {ele }}}{i_{t}},
\end{aligned}
$$

where $i_{t}$ is the initial current and $i_{\text {ele }}$ is the final residual current for all compositions of PVA/PVP : GO electrolyte system. The current versus time plots are shown in Figure 10. Initially polarization and the current rises immediately 
TABLE 5: Cell parameters of PVP/PVA : GO nanocomposite polymer films.

\begin{tabular}{lccc}
\hline Cell parameters & PVP/PVA : GO $(0.20: 0.1)$ & PVP/PVA : GO $(0.25: 0.2)$ & PVP/PVA : GO (0.30:0.3) \\
\hline Cell weight $(\mathrm{g})$ & 1.83 & 1.85 & 1.88 \\
Area of the cell $\left(\mathrm{cm}^{2}\right)$ & 1.42 & 1.42 & 1.42 \\
Open circuit voltage $(\mathrm{OCV})$ & 1.8 & 1.95 & 2.75 \\
Discharge time $(\mathrm{hrs})$ & 80 & 110 & 121 \\
Current density $\left(\mu \mathrm{A} / \mathrm{cm}^{2}\right)$ & 93.2 & 101.84 & 211.95 \\
Discharge cell $(\mu \mathrm{A} / \mathrm{h})$ & 1.35 & 1.41 & 1.60 \\
Power density $(\mathrm{W} / \mathrm{Kg})$ & 0.31 & 0.35 & 0.41 \\
Energy density $(\mathrm{Wh} / \mathrm{Kg})$ & 17.01 & 40.48 & 69.51 \\
\hline
\end{tabular}

TABLE 6: Comparison of PVP/PVA : GO nanocomposite polymer films with the other batteries.

\begin{tabular}{lccc}
\hline Solid-state electrochemical cell & Open circuit voltage $(\mathrm{OCV})$ & Discharge time for plateau region (hrs) & Reference \\
\hline $\mathrm{Na}^{+} /(\mathrm{PVA}+\mathrm{NaF}) /\left(\mathrm{I}_{2}+\mathrm{C}+\right.$ electrolyte $)$ & 2.53 & 112 & 52 \\
$\mathrm{~K}^{+} /\left(\mathrm{PVP}+\mathrm{PVA}+\mathrm{KClO}_{3}\right) /\left(\mathrm{I}_{2}+\mathrm{C}+\right.$ electrolyte $)$ & 2.00 & 89 & {$[47]$} \\
$\mathrm{K}^{+} /(\mathrm{PVP}+\mathrm{PVA}+\mathrm{KCL}) /\left(\mathrm{I}_{2}+\mathrm{C}+\right.$ electrolyte $)$ & 2.60 & 98 & {$[48]$} \\
$\mathrm{K}^{+} /(\mathrm{PVP}+\mathrm{PVA}+\mathrm{KBR}) /\left(\mathrm{I}_{2}+\mathrm{C}+\right.$ electrolyte $)$ & 2.69 & 118 & {$[49]$} \\
$\mathrm{K}^{+} /(\mathrm{PVP}+\mathrm{PVA}+\mathrm{KI}) /\left(\mathrm{I}_{2}+\mathrm{C}+\right.$ electrolyte $)$ & 2.77 & 121 & {$[49]$} \\
$\mathrm{Mg}^{+} /(\mathrm{PVA} / \mathrm{PVP}: \mathrm{GO}) /\left(\mathrm{I}_{2}+\mathrm{C}+\right.$ electrolyte $)$ & 2.75 & 121 & Present \\
\hline
\end{tabular}

and a decay of current has been observed to a steady state with a long time of polarization. This may be due to the current that initially flows across the cell at the blocking electrode under the influence of an applied voltage. The values of ionic transference number are in the range 0.94-0.99. This suggests that the charge carriers are mainly due to ions [41].

3.8. Discharge Characteristics. A solid-state polymer battery has been fabricated with the configuration of $\mathrm{Mg}^{+}$ (anode)/polymer electrolyte/(I + C + electrolyte)/(cathode) at room temperature. The anode and cathode materials were made in the form of a pellet with the thickness of $1 \mathrm{~mm}$ $[42,43]$. In the fabrication of polymer battery, magnesium metal is used as anode material and for cathode material the mixture of iodine, carbon powder, and electrolyte were used in the ratio $(5: 5: 1)$, which enhances its electronic conductivity. The discharge studies were performed for a solid-state battery for a constant load of $100 \mathrm{~K} \Omega$ with the configuration of $\mathrm{Mg}^{+}$(anode)/(PVA/PVP: GO) electrolyte/ $\left(\mathrm{I}_{2}+\mathrm{C}+\right.$ electrolyte) for different PVA/PVP : GO compositions of (0.20: 0.1$),(0.25$ : $0.2)$, and (0.30:0.3), which is shown in Figure 11. Initially, a rapid decrease in the voltage is occurred; it may be due to the polarization and the formation of thin layer of magnesium salt at the electrode/electrolyte interface [44-46]. Various cell parameters have been calculated such as power density, energy density, current density, and discharge capacity by the following equations:

$$
\text { Power density }=\frac{\mathrm{OCV} \times \mathrm{SCC}}{(\text { Weight of the cell })}(\mathrm{W} / \mathrm{kg}) \text {, }
$$

Energy density $=$ Power density $\times \operatorname{Hr}(\mathrm{Wh} / \mathrm{kg})$,

$$
\begin{gathered}
\text { Current density }=\frac{\mathrm{SCC}}{(\text { Area of the battery })}\left(\mu \mathrm{A} / \mathrm{cm}^{2}\right) \\
\text { Discharge capacity }=\left(\frac{\mathrm{SCC}}{\mathrm{Hr}}\right)\left(\mu \mathrm{Ah}^{-1}\right) .
\end{gathered}
$$

The obtained conductivity values are shown in Table 5. Figure 11 shows the discharge characteristics of the solidstate battery with composition (0.30:0.3) having highest conductivity, long durability, and exhibited better performance. It is compared with the parameters of other batteries and shown in Table 6 [47-49].

\section{Conclusions}

Nanocomposite polymer films were prepared with the combination of PVA/PVP : GO by the solution cast technique. XRD showed a sharp diffraction peak at $2 \theta=20.2^{\circ}$ that corresponds to the hexagonal lattice of (002) plane representing the semicrystalline nature of the prepared sample. Chemical complex nature of the polymer films was confirmed by FTIR analysis. The glass transition temperature and melting temperature were analyzed by using the DSC studies. The optical studies revealed that the polymer films with the lowest activation energy have the highest ionic conductivity. The conductivity was found to be maximum $\left(6.13 \times 10^{-4} \mathrm{~S} \cdot \mathrm{cm}^{-1}\right)$ for the polymer film prepared with PVA/PVP : GO (0.30:0.3) composition at room temperature. By using these polymer electrolyte films, a solid-state battery has been fabricated and the discharge characteristics were studied.

\section{Conflicts of Interest}

The authors declare that there are no conflicts of interest regarding the publication of this paper. 


\section{References}

[1] A. K. Geim and K. S. Novoselov, "The rise of grapheme," Nature Materials, vol. 6, no. 3, pp. 183-191, 2007.

[2] J. Liu, Z. Yin, X. Cao et al., "Fabrication of flexible, all-reduced graphene oxide non-volatile memory devices," Advanced Materials, vol. 25, no. 2, pp. 233-238, 2013.

[3] K. Jug, "A bond order approach to ring current and aromaticity," Journal of Organic Chemistry, vol. 48, no. 8, pp. 1344-1348, 1983.

[4] D. Y. Godovsky, "Device applications of polymer-nanocomposites," Advances in Polymer Sciences, vol. 153, pp. 163-205, Springer, Berlin, Germany, 2000.

[5] S. Guo, S. Dong, and E. Wang, "Three-dimensional Pt-on-Pd bimetallic nanodendrites supported on graphene nanosheet: facile synthesis and used as an advanced nanoelectrocatalyst for methanol oxidation," ACS Nano, vol. 4, no. 1, pp. 547-555, 2010.

[6] L. Zhang and G. Shi, "Preparation of highly conductive graphene hydrogels for fabricating supercapacitors with high rate capability," Journal of Physical Chemistry C, vol. 115, no. 34, pp. 17206-17212, 2011.

[7] N. Li, W. Cheng, K. Ren, F. Luo, K. Wang, and Q. Fu, "Oscillatory shear-accelerated exfoliation of graphite in polypropylene melt during injection molding," Chinese Journal Polymer Science, vol. 31, no. 1, pp. 98-109, 2013.

[8] L. Lin, H. Deng, X. Gao et al., "Modified resistivity-strain behavior through the incorporation of metallic particles in conductive polymer composite fibers containing carbon nanotubes," Polymer International, vol. 62, no. 1, pp. 134-140, 2013.

[9] X. Gao, S. Zhang, F. Mai et al., "Preparation of high performance conductive polymer fibres from double percolated structure," Journal of Materials Chemistry, vol. 21, no. 17, pp. 6401-6408, 2011.

[10] C. A. Di, D. C. Wei, G. Yu, Y. Q. Liu, Y. L. Guo, and D. B. Zhu, "Patterned graphene as source/drain electrodes for bottomcontact organic field-effect transistors," Advanced Materials, vol. 20, no. 17, pp. 3289-3293, 2008.

[11] M. D. Stoller, S. Park, Y. Zhu, J. An, and R. S. Ruoff, "Graphene-based ultracapacitors," Nano Letters, vol. 8, no. 10, pp. 3489-3502, 2008.

[12] Y. Xu, W. Hong, H. Bai, C. Li, and G. Shi, "Strong and ductile poly(vinyl alcohol)/graphene oxide composite films with a layered structure," Carbon, vol. 47, no. 15, pp. 3538-3543, 2009.

[13] S. Stankovich, D. A. Dikin, R. D. Piner et al., "Synthesis of graphene-based nanosheets via chemical reduction of exfoliated graphite oxide," Carbon, vol. 45, no. 7, pp. 1558-1565, 2007.

[14] R. Bissessur and S. F. Scully, "Intercalation of solid polymer electrolytes into graphite oxide," Solid State Ionics, vol. 178, no. 11-12, pp. 877-882, 2007.

[15] S. M. Zhang, L. Lin, H. Deng et al., "Synergistic effect in conductive networks constructed with carbon nanofillers in different dimensions," Express Polymer Letters, vol. 6, no. 2, pp. 159-168, 2012.

[16] A. Okada and A. Usuki, "Twenty years of polymer-clay nanocomposites," Macromolecular Materials and Engineering, vol. 291, no. 12, pp. 1449-1476, 2006.

[17] Y. Kojima, A. Usuki, M. Kawasumi et al., "Mechanical properties of nylon-6 clay hybrid," Journal Materials Research, vol. 8, no. 5, pp. 1185-1189, 1993.

[18] H. Deng, E. Bilotti, R. Zhang, J. Loos, and T. Peijs, "Effect of thermal annealing on the electrical conductivity of high-strength bi-component polymer tapes containing carbon nanofillers," Synthetic Metals, vol. 160, no. 5-6, pp. 337-344, 2010.

[19] X. Wang, L. Zhi, and K. Mullen, "Transparent conductive graphene electrodes for dye-sensitized solar cells," Nano Letters, vol. 8, no. 1, pp. 323-327, 2008.

[20] S. Morimune, T. Nishino, and T. Goto, "Poly(vinyl alcohol)/graphene oxide nanocomposites prepared by a simple eco-process," Polymer Journal, vol. 44, pp. 1056-1063, 2012.

[21] S. K. Shahenoorbasha, G. Sunita Sundari, K. Vijaya Kumar, and M. C. Rao, "Optical and dielectric properties of PVP based composite polymer electrolyte films," Journal of Polymer Science Series: A, vol. 59, no. 4, pp. 554-565, 2017.

[22] X. Zhao, Q. Zhang, and D. Chen, "Enhanced mechanical properties of graphene-based poly(vinyl alcohol) composites," Macromolecules, vol. 43, no. 5, pp. 2357-2363, 2010.

[23] L. Wan, P. Liu, T. Zhang, Y. Duan, and J. Zhang, "Exfoliation and reduction of graphene oxide at low temperature and its resulting electro capacitive properties," Journal of Materials Science, vol. 49, no. 14, pp. 4989-4997, 2014.

[24] X. Jia, C. Zhang, J. Liu et al., "Evolution of the effect of sulfur confinement in graphene-based porous carbons for use in Li-S batteries," Nanoscale, vol. 8, pp. 4447-4451, 2016.

[25] H. Kim, A. A. Abdala, and W. C. Macosko, "Graphene/polymer nanocomposites," Macromolecules, vol. 43, pp. 6515-6530, 2010.

[26] U. Khan, H. Porwal, A. O’Neill, K. Nawaz, P. May, and J. N. Coleman, "Solvent-exfoliated graphene at extremely high concentration," Langmuir, vol. 27, no. 15, pp. 9077-9082, 2011.

[27] J. L. Paredes, S. Villar-Rodil, A. Martinez-Alonso, and J. M. D. Tascon, "Graphene oxide dispersions in organic solvents," Langmuir, vol. 24, no. 19, pp. 10560-10564, 2008.

[28] Y. Matsuo, K. Tahara, and Y. Sugie, "Structure and thermal properties of poly(ethylene oxide)-intercalated graphite oxide," Carbon, vol. 35, no. 1, pp. 113-120, 1997.

[29] P. G. Liu, K. C. Gong, P. Xiao, and M. Xiao, "Preparation and characterization of poly(vinyl acetate)-intercalated graphite oxide nanocomposite," Journal of Materials Chemistry, vol. 10, no. 4, pp. 933-935, 2000.

[30] B. Zhang, S. Xu, H. Tang, and P. Wu, "Cross-linked acetyl acetonated poly(vinyl alcohol-co-vinyl acetate) nanocomposites with graphene oxide and reduced graphene oxide: a new way to modify the property of nanocomposites," RSC Advances, vol. 3, pp. 8372-8379, 2013.

[31] P. W. Davis and T. S. Shilliday, "Some optical properties of cadmium telluride," Physical Reviews, vol. 118, no. 4, pp. 1020-1022, 1960.

[32] E. M. Abdelrazek and H. M. Ragab, "Spectroscopic and dielectric study of iodine chloride doped PVA/PVP blend," Indian Journal of Physics, vol. 89, no. 6, pp. 577-585, 2015.

[33] S. K. Shahenoor Basha, G. Sunita Sundari, K. Vijay Kumar, and M. C. Rao, "Structural and dielectric properties of PVP based composite polymer electrolyte thin films," Journal of Inorganic and Organometallic Polymers and Materials, vol. 27, no. 2, pp. 455-466, 2017.

[34] A. B. Bourlinos, D. Gournis, D. Petridis, T. Szabo, A. Szeri, and I. Dekany, "Graphite oxide: chemical reduction to graphite and surface modification with primary aliphatic amines and amino acids," Langmuir, vol. 19, no. 15, pp. 6050-6055, 2003.

[35] N. Rajeswari, S. Selvasekarapandian, C. Sanjeeviraja, J. Kawamura, and S. A. Bahadur, "A study on polymer blend electrolyte based on PVA/PVP with proton salt," Polymer Bulletin, vol. 71, no. 5, pp. 1061-1080, 2014. 
[36] G. K. M. Thutupalli and S. G. Tomlin, "The optical properties of thin films of cadmium and zinc selenides and tellurides," Journal of Physics D: Applied Physics, vol. 9, no. 11, pp. 1639-1646, 1976.

[37] W. H. Kai, Y. Hirota, L. Hua, and Y. Inoue, "Thermal and mechanical properties of a poly( $\epsilon$-caprolactone)/graphite oxide composite," Journal of Applied Polymer Science, vol. 107, no. 3, pp. 1395-1400, 2008.

[38] A. L. G. Saad, W. M. Sayed, M. G. M. Ahmed, and A. M. Hassan, "Preparation and properties of some filled poly (vinyl chloride) compositions," Journal of Applied Polymer Science, vol. 73, no. 13, pp. 2657-2670, 1999.

[39] W. S. Hummers and R. E. Offman, "Preparation of graphitic oxide," Journal of American Chemical Society, vol. 80, no. 6, p. 1339, 1958.

[40] M. Hirata, T. Gotou, S. Horiuchi, M. Fujiwara, and M. Ohba, "Thin-film particles of graphite oxide 1: high-yield synthesis and flexibility of the particles," Carbon, vol. 42, no. 14, pp. 2929-2937, 2004.

[41] H. A. Becerril, J. Mao, Z. Liu, R. M. Stoltenberg, Z. Bao, and Y. Chen, "Evaluation of solution-processed reduced graphene oxide films as transparent conductors," ACS Nano, vol. 2, no. 3, pp. 463-470, 2008.

[42] H. K. Jeong, Y. P. Lee, M. H. Jin, E. S. Kim, J. J. Bae, and Y. H. Lee, "Thermal stability of graphite oxide," Chemical Physics Letters, vol. 470, no. 4-6, pp. 255-258, 2009.

[43] Z. Lin, Y. Yao, Z. Li, Y. Liu, Z. Li, and C. P. Wong, "Solventassisted thermal reduction of graphite oxide," Journal of Physical Chemistry C, vol. 114, no. 35, pp. 14819-14825, 2010.

[44] K. Hemalatha, H. Somashekarappa, and R. Somashekar, "Micro-structure, AC conductivity and spectroscopic studies of cupric sulphate doped PVA/PVP polymer composites," Advances in Material physics and Chemistry, vol. 5, no. 10, pp. 408-418, 2015.

[45] Y. Xu, Y. Wang, J. Liang et al., "A hybrid material of graphene and poly(3,4-ethyldioxythiophene) with high conductivity, flexibility, and transparency," Nano Research, vol. 2, no. 4, pp. 343-348, 2009.

[46] A. L. Saroj and R. K. Singh, "Thermal, dielectric and conductivity studies on PVA/Ionic liquid [EMIM] $\left[\mathrm{EtSO}_{4}\right]$ based polymer electrolytes," Journal of Physics and Chemistry of Solids, vol. 73, no. 2, pp. 162-168, 2012.

[47] P. Balaji Bhargav, V. Madhu Mohan, A. K. Sharma, and V. V. R. N. Rao, "Investigations on electrical properties of (PVA:NaF) polymer electrolytes for electrochemical cell applications," Current Applied Physics, vol. 9, no. 1, pp. 165-171, 2009.

[48] C. V. Subba Reddy, A. K. Sharma, and V. V. R. Narasimha Rao, "Characterization of a solid state battery based on polyblend of $\left(\mathrm{PVP}+\mathrm{PVA}+\mathrm{KBrO}_{3}\right)$ electrolyte," Ionics, vol. 10, no. 1-2, pp. 142-147, 2004.

[49] C. Umadevi, K. R. Mohan, and A. K. Sharma, "A comparative study of the discharge characteristics of (PVP/PVA) polymer blend electrolyte films doped with different potassium salts," Engineering Sciences International Research Journal, vol. 3, no. 2, pp. 38-44, 2015. 